This is the peer reviewed version of the following article: Lapko, Y. , Trianni, A. , Nuur, C. and Masi, D. (2018), In Pursuit of Closed-Loop Supply Chains for Critical Materials: An Exploratory Study in the Green Energy Sector. Journal of Industrial Ecology, which has been published in final form at https://doi.org/10.1111/jiec.12741. This article may be used for non-commercial purposes in accordance with Wiley Terms and Conditions for SelfArchiving. 


\title{
In pursuit of closed-loop supply chains for critical materials: an exploratory study in the green energy sector
}

Yulia Lapko, Andrea Trianni, Cali Nuur, Donato Masi

\begin{abstract}
A Closed-loop Supply Chain (CLSC) is considered not only as an important solution for ensuring sustainable exploitation of materials, but also as a promising strategy for securing long-term availability of materials. The latter is especially highlighted in the materials criticality discourse. Critical Raw Materials (CRMs), being exposed to supply disruptions, create an uncertain operational environment for many industries, and in particular, green energy technologies that employ multiple CRMs. However, recycling rates of CRMs are very low and engagement of companies in CLSC for CRM is limited. This study examines factors influencing CLSC for CRM development in photovoltaics panel and wind turbine technologies. The aim is to analyze how the factors manifest themselves on different companies along the supply chain and to identify enabling and bottleneck conditions for implementation of CLSC for CRM. The novelty of the study is twofold: the focus on material rather than product flows and examination of factors from a multi-actor perspective. The obtained evidence suggests that the manufacturing companies and reverse supply chain operators engaged in the study take different perspectives (product versus material) regarding development of CLSC for CRM, and thus, emphasize different factors. The findings underline the need for interactions between supply chain actors, sound competitive environment for recycling process, investment in technologies and infrastructure development, if CLSC for CRM is to be developed. The paper provides implications for practitioners and policy-makers for implementation of CLSC for CRM, and suggests prospects for further research.
\end{abstract}

Key words: closed-loop supply chain, recycling, critical materials, green energy technologies

Address correspondence to: Yulia Lapko, Via Lambruschini, 4B , building 26B, 20156 Milan, Italy. Email: yulia.lapko@polimi.it 


\section{Introduction}

Green energy technologies, aimed at achieving efficient energy consumption and reducing environmental pollution, are considered as indispensable enablers of the sustainable society (European Commission 2011; Panwar, Kaushik, and Kothari 2011). However, there are concerns about further deployment of these technologies due to compromised availability of critical materials (CRMs) they depend on (U.S. Department of Energy 2011; Moss et al. 2013; Speirs and Gross 2014). CRMs are characterized by high probability of supply constraints and high impact of supply disruption (NRC 2008; European Commission 2010; Graedel et al. 2012). This paper focuses on photovoltaics panels (PV) and wind turbines as examples of green energy technologies that employ many CRMs. According to recent estimates, the demand for both of these technologies is expected to grow significantly in the short and medium term (IEA 2013; IEA 2014). Therefore, it is important to secure their supply of CRMs they depend on (U.S. Department of Energy 2011; Moss et al. 2013; European Commission 2014).

Among different strategies proposed for mitigation of material criticality, recycling and closed-loop supply chains are particularly highlighted. A closed-loop supply chain (CLSC) is broadly defined as a system for managing integrated operations of forward and reverse supply chains (Guide, Harrison, and Van Wassenhove 2003). Being an important aspect of the circular economy and resource efficiency, CLSC is considered as a promising strategy for securing longterm availability of materials by creating additional sources of their supply via recycling (Bell, Mollenkopf, and Stolze 2013; Morley and Eatherley 2008). Recycling allows to reduce the need for mined (primary) materials (Hagelüken 2014; UNEP 2013) and negative environmental consequences of their extraction and processing (Graedel et al. 2011; Geyer et al. 2015).

However, recent research indicates that manufacturers do not view recycling and closing the loop of operations as an appealing feasible strategy (Mroueh et al. 2014; Lapko, Trucco, and Nuur 
2016), and regardless of the concerns over availability of CRMs, their recycling rates remain very low (UNEP 2013). Hagelüken (2014), while admitting technological complexity of CRM recycling, highlights the impact of market value of recovered materials on recycling process. This indicates the presence of organizational and operational constraints beyond technological issues, such as organizational complexity of recycling systems and CLSC (Guide and Van Wassenhove 2009; Hagelüken 2014).

The existing supply chain literature does not provide comprehensive indications for development of CLSC for CRM. The current research rather focuses on the sub-systems of CLSC such as reverse supply chain and reverse logistics, with limited understanding of CLSC as a whole (Govindan, Soleimani, and Kannan 2015). Publications tend to favor a manufacturer's position with only a few studies that consider multiple actors (Knemeyer, Ponzurick, and Logar 2002; Besiou and Van Wassenhove 2015). The CLSC research stream is largely focused on product recovery via remanufacturing, while examination of closed-loop systems with recycling is scant (Souza 2013). Even when studies examine recycling systems, they tend to consider a product as a unit of analysis, paying limited attention to the output of recycling in terms of types of materials (Besiou and Van Wassenhove 2015; Pagell, Wu, and Murthy 2007).

Hagelüken (2014) points out that material and product perspectives on a recycling system differ considerably in terms of priorities and scope of factors considered. Therefore, the current product perspective is not sufficient for examination of CLSC for CRM. The importance of a material perspective is highlighted in many publications focused on material flow analysis (Anctil and Fthenakis 2013; Licht, Peiro, and Villalba 2015; Elshkaki and Graedel 2014; Sprecher, Kleijn, and Kramer 2014; Allwood et al. 2011). However, that research stream lacks organizational and operational considerations that are indispensable for CLSC.

Furthermore, Hagelüken (2014) underlines particularity of a recycling system for CRMs comparing to other materials. A few available reports and publications provide important insights 
for development of such systems, but they lack empirical validation (Eurometaux 2013; UNEP 2013; Buchert, Schüler, and Bleher 2009; Reck and Graedel 2012).

This paper takes a material perspective on CLSC development and examines views of different actors along supply chains in PV and wind turbine industries regarding closing the loop of CRMs. More specifically, the paper aims at answering the following research questions:

- RQ1 How do factors for implementation of closed-loop supply chain for critical materials manifest themselves on different companies along the supply chain in photovoltaic panel and wind turbine industries?

- RQ2 What are the key enabling and bottleneck conditions for implementation of closedloop supply chain for critical materials in photovoltaic panel and wind turbine industries from the perspective of practitioners?

By considering the exploratory nature of the study, our investigation is based on qualitative case study research involving six reverse supply chain operators and four manufacturers of green energy technologies (wind turbines and photovoltaic panels) from different positions in the supply chain, all located in the EU. Building on the academic research on CLSC and available reports on CRM recycling, the factors influencing the development of CLSC for CRM are identified. These factors are further examined in the context of different supply chain actors, and implications for the development of CLSC for CRM are provided. However, the paper is not limited to examination of a certain CRM or a certain CLSC. Instead, the interest is rather in examination of issues common for different CRMs employed in green energy technologies and distinguish conditions for companies to engage in developing CLSC for CRM.

The rest of the paper is organized as follows. Next section provides the literature background on factors affecting CLSC and CRM recycling. Then, the research methodology is described. In the 
following two sections the empirical findings are presented and discussed. The paper ends with conclusions, prospects for further research and implications for practitioners and policy-makers.

\section{Factors for implementation of closed-loop supply chain for critical materials}

Existing literature provides very few implications for development of CLSC with recycling. When considering the factors affecting CLSC implementation, the research stream is rather dominated by CLSC sub-systems such as reverse logistics (e.g. Carter and Ellram 1998; Lau and Wang 2009) and reverse supply chain (e.g. Rahman and Subramanian 2012); with a few publications investigating CLSC (e.g. Besiou and Van Wassenhove 2015; Miemczyk et al. 2016).

While some publications are specifically focused on the examination of factors for implementation of CLSC (or its sub-systems) (e.g. Knemeyer et al. 2002; Lau and Wang 2009), other papers provide implications for factors without explicit aim of their development or analysis (e.g. Tanskanen 2013; Thierry et al. 1995) or do not provide conceptual/theoretical rationale for their selection (Besiou and Van Wassenhove 2015). In addition, even when studies aim to provide implications for recycling, they largely ground on remanufacturing literature (e.g. Rahman and Subramanian 2012; Stindt et al. 2016). Furthermore, when considering implications for CRMs, only a few publications can be found (Buchert, Schüler, and Bleher 2009; Hagelüken 2014). Studies rather focus on recycling of other materials (Geyer and Jackson 2004; Miemczyk, Howard, and Johnsen 2016; Simpson 2010) or on a product as a flow unit and mass-recycling without attention to a precise metal output (e.g. Roy and Whelan 1992; Tanskanen 2013).

Scholars suggest different sets of factors affecting CLSC (or its sub-systems) and propose various classifications, such as external versus internal (Carter and Ellram 1998; Rogers and TibbenLembke 1999), or strategic versus operational (Dowlatshahi 2000). Lau and Wang (2009) and Knemeyer et al. (2002) combine both approaches and identify external and internal factors, where the latter are further characterized by strategic and operational considerations. Rahman and 
Subramanian (2012) classify factors based on balanced score card dimensions, while Stindt et al. (2016) adopt Porter's five forces (Porter 1979) for the same purpose.

The scope of each individual publication is still limited by the perspective taken and a list of factors considered. In order to obtain a comprehensive view on closing the loop of CRMs, a comparative analysis of factors in the existing studies was conducted. We consolidated insights from different studies merging similar factors into distinctive categories.

Ten factors are generally viewed as important for CLSC development with the focus on CRM recycling: F1 - technical feasibility of recycling, F2- availability of items for recycling, F3market for recycled materials, F4- economic feasibility, F5-competition, F6- information exchange and supply chain transparency, F7- engagement of supply chain actors, F8- established industrial infrastructure, F9- legislation, F10- public engagement. Description and distribution of the factors in the literature is presented in Table 1 below.

Technical feasibility of recycling (F1) depends on accessibility of materials due to composition of products in terms of material types and mixes, interfaces between components and different materials (Thierry et al. 1995; Hagelüken 2014). They determine ease of dismantling and set physical/chemical limitations for recycling (Buchert, Schüler, and Bleher 2009). Complexity of material mixes often implies a necessity to set priorities for recovery of certain materials over others (Hagelüken 2014; UNEP 2013).

Availability of items for recycling (F2) refers to quantity, quality, heterogeneity, location (product mobility) of returned items, which are subject to consumer behaviour, business to business (B2B) or business to customer (B2C) markets (Hagelüken 2014; Stindt et al. 2016), dissipation in use (Hagelüken 2014; Buchert, Schüler, and Bleher 2009), alternative recovery processes (Stindt et al. 2016), shipment of wastes out of jurisdiction (Eurometaux 2013; Tanskanen 2013). 
Market for recycled materials (F3) is generally driven by material price (Simpson, 2010; Besiou and Van Wassenhove, 2015) and demand growth (Rahimifard et al. 2009; Geyer and Jackson 2004; Stindt et al. 2016) coming from original producers, other companies in the supply chain (e.g. suppliers) or from companies in other supply chains (Thierry et al. 1995).

Economic feasibility (F4) is comprised of the overall cost-benefits analysis. It will be different for different actors in the supply chain depending on the extent of operations and involvement into material recovery. For example, investments in product design for manufacturers (Dowlatshahi 2000; Stindt et al. 2016) and costs of separation and recycling processes for recycling operators (Hagelüken 2014; Tanskanen 2013).

Competition (F5) refers to the impact of competitors and competitive environment on product recovery. Different supply chain actors have different competitors and different competitive environments. According to several studies, competition transforms in CLSC: Lau and Wang (2009) and Simpson (2010) indicate opportunities for manufacturers to collaborate in CLSC with competitors from a forward supply chain; and Pagell, Wu, and Murthy (2007) caution against a possibility of a competition between recyclers and primary material suppliers. However, researchers advocate for CLSC and recycling as a source of competitive advantage (Pagell, $\mathrm{Wu}$, and Murthy 2007; Rahman and Subramanian 2012; Bell, Mollenkopf, and Stolze 2013). In particular, Pagell, $\mathrm{Wu}$, and Murthy (2007) highlight in-house recycling as an opportunity for manufacturers to keep the product/material out of other channels, unavailable to competitors.

Information exchange and supply chain transparency (F6) concerns sharing/exchanging information on product composition (Thierry et al. 1995), material flows and performance indicators both along the supply chain (Pagell, Wu, and Murthy 2007; Simpson 2010) and between different supply chains (Roy and Whelan 1992) in order to eliminate asymmetry of information (Simpson, 
2010) and enable transparency (Hagelüken 2014; Eurometaux 2013), coordination (Rahman and Subramanian 2012) and control (Miemczyk, Howard, and Johnsen 2016).

Engagement of supply chain actors (F7) refers to alignment of incentives, sharing of costs and responsibilities among companies along the supply chain, including cooperation with competitors in the forward supply chain (Lau and Wang 2009; Simpson 2010). Pagell, Wu, and Murthy (2007) highlighted the importance of high involvement of manufacturers into recovery processes (e.g., control of resources, optimized product design for recovery process etc.). Moreover, they point out the need to involve suppliers in developing the operating channel, as recyclers can turn into competitors of existing suppliers. Conceptually, engagement of actors (F7) differs from information exchange (F6). For example, while collaboration requires information exchange (e.g. Cao and Zhang 2011), the information exchange does not necessarily imply collaboration, incentive alignment of actors, sharing of costs etc.

Established industrial infrastructure (F8) refers to facilities, capacity, technological level at each stage of CLSC (collection, mechanical processing, metallurgical processing) and set predisposition for possible leakage of collected items to non-functional recycling (Hagelüken 2014; UNEP 2013; Eurometaux 2013).

Legislation (F9) refers to the institutional framework including regulation, policies and directives that set operational environment of different actors along the supply chain. For example, these are recycling targets (Roy and Whelan 1992) and product take-back requirements (Thierry et al. 1995). However, recently, scholars indicate the need for legislation requirements directed towards all supply chain actors, not only for producers and/or recyclers (Tanskanen 2013; Rahimifard et al. 2009). 
Table 1. Factors influencing development of CLSC for CRM

\begin{tabular}{|c|c|c|c|c|c|c|c|c|c|c|c|c|c|c|c|c|c|c|c|c|c|}
\hline & 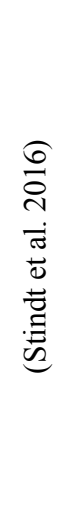 & 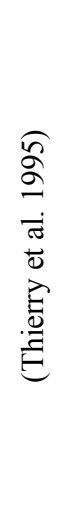 & 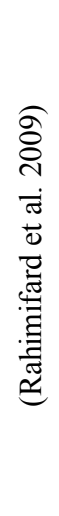 & 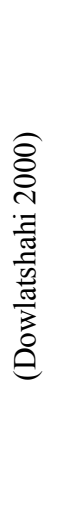 & 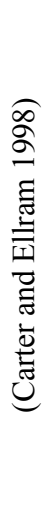 & 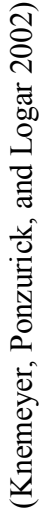 & 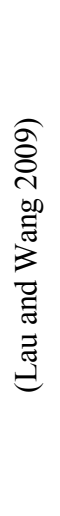 & 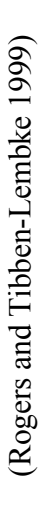 & 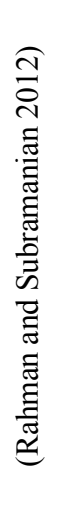 & 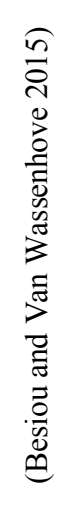 & 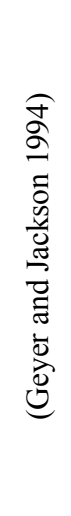 & 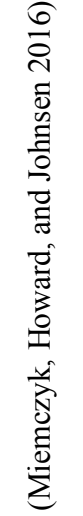 & 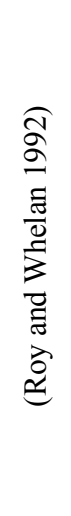 & 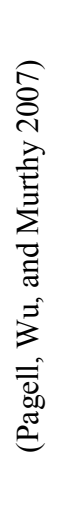 & 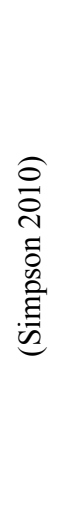 & 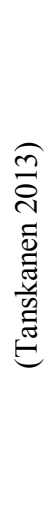 & 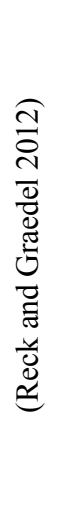 & 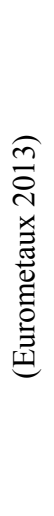 & 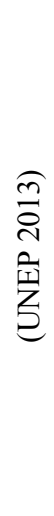 & 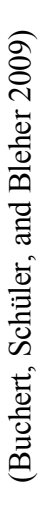 & 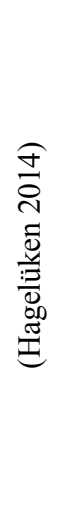 \\
\hline Scope* & $\begin{array}{l}\text { Rev. } \\
\text { mark }\end{array}$ & $\begin{array}{c}\text { Prod. } \\
\text { rec. }\end{array}$ & $\begin{array}{c}\text { Prod. } \\
\text { rec }\end{array}$ & RL & RL & RL & RL & RL & RSC & CLSC & CLSC & CLSC & CLSC & $\begin{array}{l}\text { Rec. } \\
\text { man. }\end{array}$ & $\begin{array}{l}\text { Rec. } \\
\text { man. }\end{array}$ & $\begin{array}{l}\text { Rec. } \\
\text { man. }\end{array}$ & $\begin{array}{l}\text { Rec. } \\
\text { syst }\end{array}$ & $\begin{array}{l}\text { Rec. } \\
\text { syst } \\
\end{array}$ & $\begin{array}{l}\text { Rec. } \\
\text { syst }\end{array}$ & $\begin{array}{l}\text { Rec. } \\
\text { syst }\end{array}$ & $\begin{array}{l}\text { Rec. } \\
\text { syst }\end{array}$ \\
\hline Perspective** & M & M & M & M & M & $\begin{array}{l}\mathrm{M} / \\
\mathrm{A}\end{array}$ & M & M & $\mathrm{R}$ & $\mathrm{M} / \mathrm{A}$ & $\mathrm{M} / \mathrm{F}$ & $\mathrm{M}+\mathrm{R} / \mathrm{S}$ & $\mathrm{M} / \mathrm{A}$ & M & M & M & $\mathrm{R} / \mathrm{S}$ & $\mathrm{R} / \mathrm{S}$ & $\mathrm{R} / \mathrm{S}$ & $\mathrm{R} / \mathrm{S}$ & $\mathrm{R} / \mathrm{S}$ \\
\hline $\begin{array}{l}\text { F1 - Technical feasibility of } \\
\text { recycling }\end{array}$ & $\bullet$ & $\bullet$ & $\bullet$ & - & & $\bullet$ & $\bullet$ & & & - & $\bullet$ & & $\bullet$ & & & • & $\bullet$ & - & - & - & $\bullet$ \\
\hline $\begin{array}{l}\text { F2- Availability of items for } \\
\text { recycling }\end{array}$ & $\bullet$ & $\bullet$ & $\bullet$ & & & & & • & $\bullet$ & $\bullet$ & • & & & & • & $\bullet$ & $\bullet$ & $\bullet$ & & $\bullet$ & $\bullet$ \\
\hline $\begin{array}{l}\text { F3 - Market for recycled } \\
\text { materials }\end{array}$ & $\bullet$ & $\bullet$ & • & & & & & & & $\bullet$ & • & & $\bullet$ & & • & $\bullet$ & & & & & \\
\hline F4 - Economic feasibility & $\bullet$ & $\bullet$ & $\bullet$ & $\bullet$ & & $\bullet$ & $\bullet$ & $\bullet$ & $\bullet$ & $\bullet$ & $\bullet$ & & & $\bullet$ & $\bullet$ & $\bullet$ & $\bullet$ & $\bullet$ & $\bullet$ & $\bullet$ & $\bullet$ \\
\hline F5 - Competition & - & & & & $\bullet$ & • & • & & & $\bullet$ & & & & • & • & & • & $\bullet$ & $\bullet$ & & $\bullet$ \\
\hline $\begin{array}{l}\text { F6 - Information exchange and } \\
\text { supply chain transparency }\end{array}$ & & $\bullet$ & & & & & $\bullet$ & $\bullet$ & $\bullet$ & & & $\bullet$ & $\bullet$ & $\bullet$ & $\bullet$ & $\bullet$ & • & • & & & • \\
\hline $\begin{array}{l}\text { F7 - Engagement of supply chain } \\
\text { actors }\end{array}$ & & $\bullet$ & $\bullet$ & & $\bullet$ & $\bullet$ & $\bullet$ & $\bullet$ & $\bullet$ & & & $\bullet$ & $\bullet$ & $\bullet$ & $\bullet$ & $\bullet$ & & $\bullet$ & & & $\bullet$ \\
\hline $\begin{array}{l}\text { F8- Established industrial } \\
\text { infrastructure }\end{array}$ & $\bullet$ & & $\bullet$ & $\bullet$ & & $\bullet$ & $\bullet$ & & • & & & • & & & • & $\bullet$ & $\bullet$ & $\bullet$ & $\bullet$ & $\bullet$ & $\bullet$ \\
\hline F9 - Legislation & $\bullet$ & $\bullet$ & $\bullet$ & $\bullet$ & • & $\bullet$ & $\bullet$ & $\bullet$ & $\bullet$ & $\bullet$ & & $\bullet$ & $\bullet$ & & & $\bullet$ & $\bullet$ & $\bullet$ & $\bullet$ & • & $\bullet$ \\
\hline F10 - Public engagement & - & & • & & - & - & $\bullet$ & • & • & & & & & & & • & - & & & & \\
\hline
\end{tabular}


Public engagement (F10) corresponds to awareness of product consumers and society in general about benefits of recycling (Rahman and Subramanian 2012), their willingness to return products (Stindt et al., 2016), awareness about infrastructure for products collection (Tanskanen 2013; Rahimifard et al. 2009), intention to preserve the environment (Rahman and Subramanian 2012), perception of quality and safely of employment of recycled materials (Rahimifard et al. 2009).

\section{Research methodology}

Previous studies examining factors affecting CLSC (or its sub-systems) largely adopt a qualitative case based research design engaging with different supply chain actors (e.g. Besiou and Van Wassenhove, 2015; Lau and Wang 2009; Rahman and Subramanian 2012). The preference for qualitative research approach is driven by the opportunity to examine and gain in-depth understanding of a complex phenomenon such as CLSC (Eisenhardt and Graebner 2007; Yin 2009). Moreover, Souza (2013) highlights the need for more empirical studies on CLSC, as currently this research stream is dominated by simulation and modelling (Govindan, Soleimani, and Kannan 2015)

Given the objectives and exploratory nature of this paper, a qualitative case study research design is chosen. In order to examine the conditions enabling CLSC for CRM development accounting for perspectives of different supply chain actors, the research methodology takes inspiration from the multi-sited ethnography approach (Burrell 2009; Green 1999; Nadai and Maeder 2005). On the one hand, this approach provides means for comparison of the same processes at different sites (e.g. for identifying the differences and commonalities that exist between companies with different supply chain positions). On the other hand, it allows to investigate a 
complex phenomenon via collecting evidence from multiple sites (different companies) allowing for more comprehensive understanding of CLSC in a whole.

As the ultimate aim is to examine perspectives of different companies in the supply chain that can potentially be part of CLSC, the unit of analysis is a single organization that employs critical materials for manufacturing products/components or that processes end-of-life products containing those materials.

\section{Selection of companies}

The focus on photovoltaic panels (PV) and wind turbines technologies is anchored in their importance for reduction of Green House Gas (GHG) emissions, transition to a low carbon economy and enabling sustainable development of society (Moss et al. 2013; Speirs and Gross 2014). These two applications employ the majority of CRMs used in green energy technologies (e.g. indium, gallium, tellurium in PV; rare earth elements in wind turbines). This allows to examine and obtain implications for development of CLSC for different CRMs rather than development of CLSC for a precise CRM. Since the study's aim is to examine the views of different actors on CLSC for CRM development, the selected companies include component and final product manufacturers of wind turbines and PV, and reverse supply chain operations processing such products (or which can potentially do so). Manufacturing companies and recyclers are regarded as the actors who have the most power to shape CLSC. Engagement of companies from different industries (PV and wind turbines) and different supply chains enable to obtain implications for CLSC for CRM development rather than to account for an industry and/or a certain supply chain contingencies (c.f. Pagell and $\mathrm{Wu}$ 2009). Geographical scope is important for selection of companies, because materials criticality is subject to external environment such as a geopolitical location (NRC 2008; European Commission 2010; Graedel et al. 2012). This study examines companies located within the EU and 
grounds on the list of CRMs provided by the European Commission (2014). Figure 1 depicts the companies selected according to industry and supply chain positions.

In total four manufacturing companies and six reverse supply chain operators were selected. These companies cover all main functions along CLSC in a way that each supply chain position (function) is also represented by at least two companies. The majority of companies perform several functions along the supply chain: the wind turbine manufacturers have integrated operations and both produce components and assemble the final products; some recyclers perform other activities in the supply chain as collection of returns, material manufacturing, mining and refining. The selected companies have leading positions at a nation and/or the EU and/or the global level. Only few of the selected companies are directly involved in PV or wind turbines recycling, however, all of them can potentially be part of CLSC for CRM in PV and wind turbines technologies.

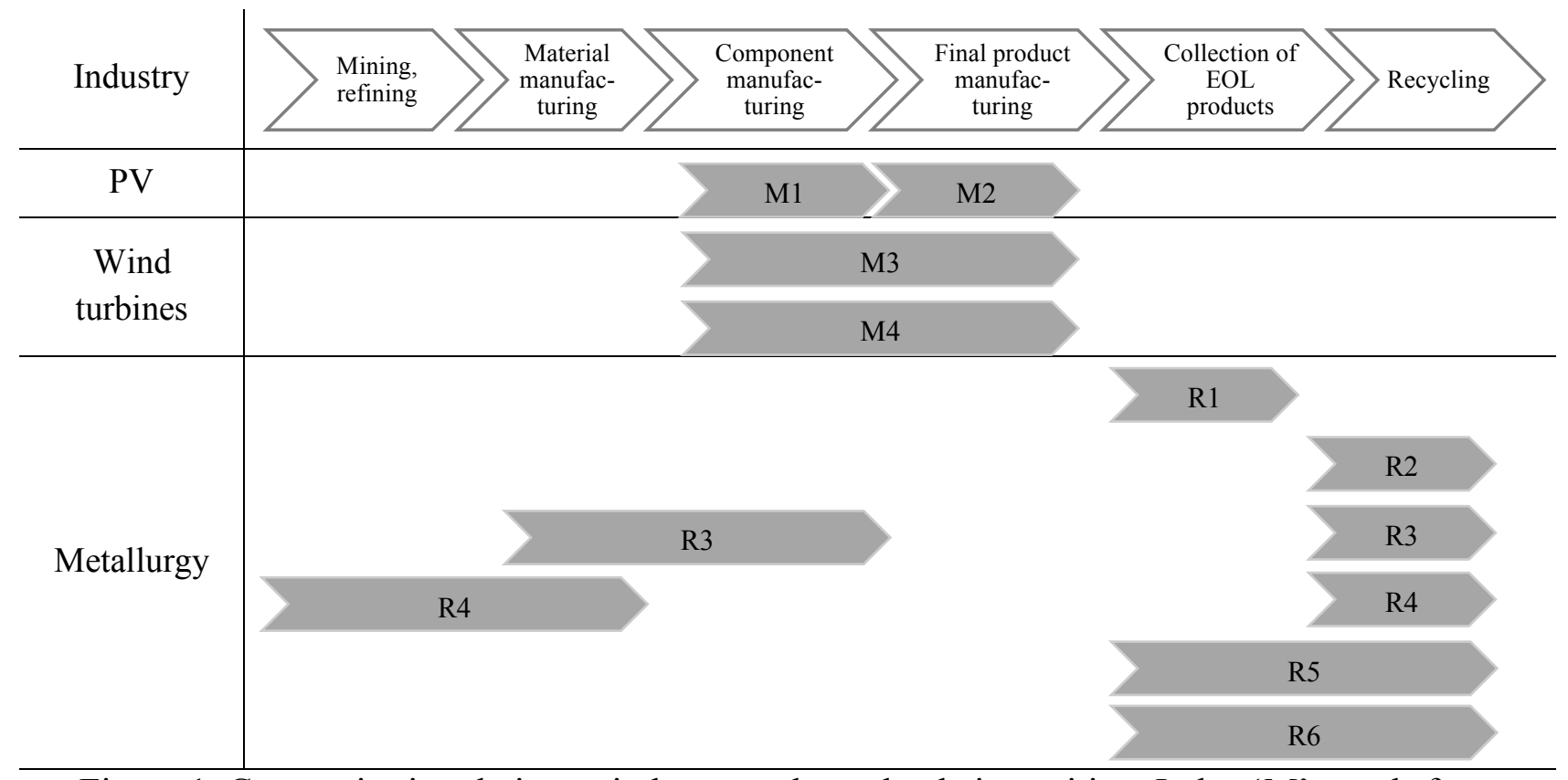

Figure 1. Companies in relation to industry and supply chain position. Index ' $M$ ' stands for a manufacturing company and index ' $R$ ' refers to a reverse supply chain operator. 


\section{Data collection}

The main sources of data collection were semi-structured interviews with company representatives. A semi-structured interview protocol was employed at all companies in order to ensure that the key research topics would be addressed and also to allow to gain additional information specific to a certain company or to a supply chain position (Eisenhardt 1989; Saunders, Lewis, and Thornhill 2009). The interview protocol covered the following key topics.

- Engagement of a company in CRM recycling and CLSC for CRM (use of CRM recycled in products, product design enabling CRM recycling, collection of end-of-life products, collaboration with other supply chain actors etc.).

- Factors influencing implementation of CLSC for CRM, current enabling and bottleneck conditions. It should be noted that the list of factors obtained via literature review was not shared with interviewees in order to avoid possible bias. Instead, interviewer(s) guided the discussion in order to address all issues listed via the follow-up questions.

- Changes required to foster CLSC for CRM development such as actions taken by other supply chain actors: suppliers, recyclers, government, manufacturers.

- A company's perspective towards CRM recycling and CLSC for CRM as a strategy for mitigation of materials criticality (concerns over availability of CRMs, preference to other strategies).

The interviewees were selected based on their expertise and ability to provide information about a company's engagement into CRM management and CLSC processes. The functional roles of interviewees differ among companies, as each company has its particular organizational structure, division of responsibilities and position titles. The interviews were conducted with company representatives from sustainability, purchasing and supply, R\&D functions at middle management level, as well as with senior managers that have overall knowledge on the business (see Table 2). 
Individual interviews lasted between 30 and 90 minutes and were conducted via phone by the authors. With permission of the interviewees, the interviews were recorded and transcribed for further data analysis. In addition, notes taken by interviewers were also further processed in data analysis. In order to avoid investigator bias, interviews were conducted by at least two researchers whenever possible.

The secondary data such as reports of companies and information on the webpages of companies were collected and analyzed upon availability ensuring that for each company the primary data is supported with the secondary one. This approach allowed not only to enrich data, but also to ensure data triangulation and reduce interviewee bias (Eisenhardt 1989). The search for data in the secondary sources followed the lines of inquiry of the interview protocols. All data were collected in 2015 and 2016.

Table 2. Profile of the companies interviewed.

\begin{tabular}{|l|l|l|l|l|l|l|}
\hline Company & $\begin{array}{l}\text { Supply chain } \\
\text { position }\end{array}$ & Industry & $\begin{array}{l}\text { Revenue } \\
\text { (millions } \\
\text { euro) }\end{array}$ & $\begin{array}{l}\text { Number of } \\
\text { employees }\end{array}$ & $\begin{array}{l}\text { Interviewee } \\
\text { position }\end{array}$ & $\begin{array}{l}\text { Date of } \\
\text { interview }\end{array}$ \\
\hline$[\mathrm{M} 1]$ & $\begin{array}{l}\text { Component } \\
\text { manufacturer }\end{array}$ & PV & $<50$ & $150-250$ & $\begin{array}{l}\text { Middle } \\
\text { management level }\end{array}$ & $\begin{array}{l}\text { June } \\
2016\end{array}$ \\
\hline$[\mathrm{M} 2]$ & $\begin{array}{l}\text { Final product } \\
\text { manufacturer }\end{array}$ & PV & n.a. & $50-150$ & $\begin{array}{l}\text { Middle } \\
\text { management level }\end{array}$ & $\begin{array}{l}\text { May } \\
2016\end{array}$ \\
\hline$[$ M3] & $\begin{array}{l}\text { Component } \\
\text { and final } \\
\text { product } \\
\text { manufacturer }\end{array}$ & $\begin{array}{l}\text { Wind } \\
\text { turbines }\end{array}$ & n.a. & $\begin{array}{l}17500- \\
18000\end{array}$ & $\begin{array}{l}\text { Senior } \\
\text { management level }\end{array}$ & 2016 \\
\hline$[$ M4] & $\begin{array}{l}\text { Component } \\
\text { and final } \\
\text { product } \\
\text { manufacturer }\end{array}$ & $\begin{array}{l}\text { Wind } \\
\text { turbines }\end{array}$ & $\begin{array}{l}4500- \\
6000\end{array}$ & $\begin{array}{l}14000- \\
14500\end{array}$ & $\begin{array}{l}\text { Middle } \\
\text { management level }\end{array}$ & $\begin{array}{l}\text { May } \\
2016\end{array}$ \\
\hline $\begin{array}{l}\text { Collector of } \\
\text { end-of-life } \\
\text { products, } \\
\text { Producer } \\
\text { Responsibility } \\
\text { Organization }\end{array}$ & $\begin{array}{l}\text { Metal- } \\
\text { lurgy }\end{array}$ & $\begin{array}{l}\text { Not-for- } \\
\text { profit }\end{array}$ & $100-250$ & $\begin{array}{l}\text { Senior } \\
\text { management level }\end{array}$ & $\begin{array}{l}\text { June } \\
2016\end{array}$ \\
\hline
\end{tabular}




\begin{tabular}{|c|c|c|c|c|c|c|}
\hline [R2] & Recycler & $\begin{array}{l}\text { Metal- } \\
\text { lurgy }\end{array}$ & n.a. & $<50$ & $\begin{array}{l}\text { Senior } \\
\text { management level }\end{array}$ & $\begin{array}{l}\text { June } \\
2016\end{array}$ \\
\hline [R3] & $\begin{array}{l}\text { Recycler, } \\
\text { material and } \\
\text { component } \\
\text { manufacturer }\end{array}$ & $\begin{array}{l}\text { Metal- } \\
\text { lurgy }\end{array}$ & $\begin{array}{l}1500- \\
3000\end{array}$ & $\begin{array}{l}9500- \\
10000\end{array}$ & $\begin{array}{l}\text { Senior } \\
\text { management level }\end{array}$ & $\begin{array}{l}\text { May } \\
2015\end{array}$ \\
\hline [R4] & $\begin{array}{l}\text { Recycler, } \\
\text { miner, smelter, } \\
\text { material } \\
\text { manufacturer }\end{array}$ & $\begin{array}{l}\text { Metal- } \\
\text { lurgy }\end{array}$ & $\begin{array}{l}3000- \\
4500\end{array}$ & $5000-5500$ & $\begin{array}{l}\text { Middle } \\
\text { management level }\end{array}$ & Oct 2015 \\
\hline [R5] & $\begin{array}{l}\text { Collector of } \\
\text { end-of-life } \\
\text { products, } \\
\text { recycler }\end{array}$ & $\begin{array}{l}\text { Metal- } \\
\text { lurgy }\end{array}$ & n.a. & $150-250$ & $\begin{array}{l}\text { Senior } \\
\text { management level }\end{array}$ & $\begin{array}{l}\text { Nov } \\
2015\end{array}$ \\
\hline [R6] & $\begin{array}{l}\text { Collector of } \\
\text { end-of-life } \\
\text { products, } \\
\text { recycler }\end{array}$ & $\begin{array}{l}\text { Metal- } \\
\text { lurgy }\end{array}$ & $\begin{array}{l}1500- \\
3000\end{array}$ & $3000-3500$ & $\begin{array}{l}\text { Senior } \\
\text { management level }\end{array}$ & $\begin{array}{l}\text { May } \\
2016\end{array}$ \\
\hline
\end{tabular}

\section{Data analysis}

When the data collection was finished, the coding of the obtained data was performed in order to identify empirical evidence in relation to the factors influencing CLSC for CRM development. In particular, the basic coding process was as follows. Each factor in Table 1 was labelled with a code from F1 to F10. Then, the interviews and secondary data were examined in order to assign the codes to the corresponding evidence. In addition, implications for enabling and bottleneck conditions were also marked with the codes corresponding to the associated factors.

Once the coding process was completed, the data was analyzed from different perspectives and at different levels (Miles and Huberman 1994):

- within each company, for investigating the presence of specific factors connected to CLSC for CRM development and their roles; 
- within each supply chain position, for examining commonalities and differences regarding specific factors and their roles;

- within each factor, for highlighting commonalities and differences as indicated by different companies.

\section{Rigor of the study}

Eight trustworthiness criteria for qualitative inductive research were used to estimate the rigor of the study, by taking inspiration from previous research (Flint, Woodruff, and Gardial 2002; Mollenkopf, Russo, and Frankel 2007; Lin and Zhou 2011; Manuj and Mentzer 2008). These criteria are: credibility, transferability, dependability, confirmability and integrity, taken from interpretive research approach (Hirschman 1986; Wallendorf and Belk 1989; Guba 1981); and fit, understanding and generality, adopted from the grounded theory (Strauss and Corbin 1990). Table 3 shows that the methodology employed met these criteria.

Table 3. Rigor of the study: evaluation criteria and steps taken

\begin{tabular}{|l|l|}
\hline Criteria and explanation & Steps to address the criteria \\
results appear to be acceptable & $\begin{array}{l}\text { No contradictory evidence was identified via triangulation } \\
\text { of data sources (interviews and secondary sources). } \\
\text { The interviewees were asked to verify interpretations of } \\
\text { data obtained from both interviews and reports. }\end{array}$ \\
\hline $\begin{array}{l}\text { Transferability (extent to which the data) } \\
\text { findings from a study in one context }\end{array}$ & $\begin{array}{l}\text { Selected companies represent variations in type of } \\
\text { industries, supply chain positions, employed critical } \\
\text { will apply to other contexts) }\end{array}$ \\
\hline $\begin{array}{l}\text { Dependability (extent to which the } \\
\text { findings are unique to time and }\end{array}$ & $\begin{array}{l}\text { All interviewees have expertise and knowledge to provide } \\
\text { information regarding a company's engagement in CRM }\end{array}$ \\
\hline
\end{tabular}




\begin{tabular}{|c|c|}
\hline $\begin{array}{l}\text { place; the stability or consistency of } \\
\text { explanations) }\end{array}$ & $\begin{array}{l}\text { recycling and CLSC for CRM, to discuss factors } \\
\text { influencing development of CLSC for CRM. }\end{array}$ \\
\hline $\begin{array}{l}\text { Confirmability (extent to which } \\
\text { interpretations are the result of the } \\
\text { participants and the phenomenon as } \\
\text { opposed to researcher bias) }\end{array}$ & $\begin{array}{l}\text { Triangulation of data sources: interviews and secondary } \\
\text { data. } \\
\text { The interviewees were asked to verify interpretations of } \\
\text { data obtained from both interviews and reports. }\end{array}$ \\
\hline $\begin{array}{l}\text { Integrity (extent to which } \\
\text { interpretations are influenced by } \\
\text { misinformation or } \\
\text { evasions by participants) }\end{array}$ & $\begin{array}{l}\text { Confidentiality of obtained data was assured to all } \\
\text { interviewees. } \\
\text { No contradictory evidence was identified via triangulation } \\
\text { of data sources. }\end{array}$ \\
\hline $\begin{array}{l}\text { Fit (extent to which findings fit with } \\
\text { the substantive area under } \\
\text { investigation) }\end{array}$ & $\begin{array}{l}\text { Ensured by credibility, dependability, and confirmability } \\
\text { of the study. }\end{array}$ \\
\hline $\begin{array}{l}\text { Understanding (extent to which } \\
\text { participants accept results as possible } \\
\text { representations of their world) }\end{array}$ & $\begin{array}{l}\text { The interviewees were asked to verify interpretations of } \\
\text { data obtained from both interviews and reports. }\end{array}$ \\
\hline $\begin{array}{l}\text { Generality (extent to which findings } \\
\text { discover multiple aspects of the } \\
\text { phenomenon) }\end{array}$ & $\begin{array}{l}\text { Interviews lasted sufficient length to obtain explicit } \\
\text { replies on posed questions ( } 30-90 \mathrm{~min}) \text {. } \\
\text { Semi-structured interviews allow obtaining additional data } \\
\text { specific to a certain company. }\end{array}$ \\
\hline
\end{tabular}

\section{Findings}

Table 4 presents the factors indicated by the companies interviewed as relevant for development of CLSC for CRM. Each factor is described further in the text. 
Table 4. Factors influencing CLSC for CRM as indicated by interviewed companies

\begin{tabular}{|c|c|c|c|c|c|c|c|c|c|c|c|}
\hline Company & Industry & F1 & F2 & F3 & F4 & F5 & F6 & F7 & F8 & F9 & F10 \\
\hline [M1] & PV & $\bullet$ & & & & & & & & & \\
\hline [M2] & PV & - & & & & & & & & & \\
\hline [M3] & Wind turbines & & $\bullet$ & & & & & & & & \\
\hline [M4] & Wind turbines & - & & & & & & $\bullet$ & & & \\
\hline [R1] & Metallurgy & $\bullet$ & $\bullet$ & - & & & & & $\bullet$ & $\bullet$ & $\bullet$ \\
\hline [R2] & Metallurgy & & $\bullet$ & $\bullet$ & $\bullet$ & & & & & & \\
\hline [R3] & Metallurgy & $\bullet$ & - & $\bullet$ & $\bullet$ & $\bullet$ & $\bullet$ & $\bullet$ & $\bullet$ & $\bullet$ & $\bullet$ \\
\hline [R4] & Metallurgy & - & & - & - & & & & & & \\
\hline [R5] & Metallurgy & $\bullet$ & & $\bullet$ & $\bullet$ & & & & & & \\
\hline [R6] & Metallurgy & $\bullet$ & $\bullet$ & & $\bullet$ & - & & $\bullet$ & $\bullet$ & & \\
\hline
\end{tabular}

Technical feasibility of recycling $(F 1)$ is the most commonly mentioned factor among interviewed companies. Nevertheless, it appears that interviewed companies consider it differently. On the one hand, the reverse supply chain operators indicate that the complexity of the product design (the small concentration and complex mixes of materials) affects the thermodynamic viability for recycling processes; on the other hand, the interviewed manufacturing companies state that the recycling of CRMs is not possible due to the lack of appropriate recycling technologies. Company M4 puts it as: "a possible way of achieving sustainable utilization of rare earth elements (REE) is to recycle these materials from electric motors. But so far there are no practical methods for doing so". Although M4 reported about initiatives to develop REE recycling with other stakeholders, the company primarily focuses its R\&D activities on decreasing use of REE in product design and substitution of these materials.

The interviewed manufacturers consider the overall product recyclability that is rather high for PV and wind turbine technologies (70-90\%). Taking mass recycling perspective, they pay little attention to kinds of materials recycled and their quality. According to M3, it is too early to think about product recycling, as life cycle of wind turbines is very long (30 years from now) and by that 
time recycling technology might become more advanced. Moreover, M3 is more interested in product life extension via reconditioning and reuse in emerging markets.

However, Rahimifard et al. (2009) highlight that products should be designed in accordance with already established recycling technologies. In general, previous research sides with recyclers highlighting the need for product redesign in order to facilitate material recovery (e.g. Thierry et al. 1995; Ciacci et al. 2015; Peck et al. 2015; Tanskanen 2013). M2 indicates that alternative PV design might enhance disassembly, but at the same time, decrease profitability of recyclers as "paying" material (aluminum) will be removed.

Availability of items for recycling (F2) is an important prerequisite for recycling operations. Reverse supply chain actors (R1, R2, R3, R6) indicate low volumes of scrap of PV and wind turbines due to long product life cycle as well as inefficient collection systems (e.g. returns are not collected due to lack of infrastructure, its insufficient capacity) (F8). For example, R2 indicates that PV recycling comprises only ten percent of overall activities: "our capacity is 50 tons per month but, in reality, what arrive to us is about five tons per month of solar panels"; and that it would be impossible for a company to run business only on PV scrap. All reverse supply chain companies interviewed rely on multiple sources (e.g. product types) and try to actively source items for recycling. Miemczyk et al. (2016) provide similar evidence indicating increase of operational complexity caused by diversity of inputs.

Although a growing number of products sold may appear to be a driver for recycling, R3 and R6 argue the opposite. Firstly, the growing number of product items might not indicate the growing volumes of materials due to product miniaturization (and dematerialization). R6 indicates that it experiences the shrinking input of recycling and decreasing profit (F4). Secondly, long product life cycle creates uncertainty for reverse supply chain operators about time and volumes of returns. Moreover, there is no warranty that the products currently being sold will be collected at the end of their life and will be brought for functional recycling (F10). Allwood et al. (2013) point out that 
both dematerialization and product life extension inhibit recycling, and the researchers characterize them as conflictual material efficiency strategies.

Market for recycled materials (F3) is an important concern for some recyclers interviewed. They indicate high price instability of CRMs (R4, R5) as well as absence of market demand for recycled materials (R5). The manufacturers interviewed state that they cannot use recycled CRMs for PV and wind turbine production due to their lower quality (purity). Companies R1 and R2 also indicate that recycled CRMs could be utilized in other applications, but not in PV and wind turbines. In addition, R2 notices that component/product manufacturers are not the customers of recyclers, as they do not purchase raw materials, but semi-finished products, and thus do not recognize incentives to invest in that market. However, R3 is an example of a company with integrated manufacturing and recycling operations. For example, R3 recycles germanium from multiple applications (including PV) and employs it for production of wafers for PV. Rahimifard et al. (2009) point out that companies tend to invest in recycling only when the technologies and market are developed; instead, it is necessity to establish "pull recycling" when it is driven by demand for recycled materials.

The obtained evidence on inputs for $(F 2)$ and outputs of $(F 3)$ recycling indicate that boundaries of CLSC span across different supply chains, and resemble rather a network: items for recycling come from multiple sources and recycled materials are employed in multiple applications. Given this mode of operations, we agree with Geyer et al. (2015) that for systems with a focus on material flows, it is not useful to identify a closed loop within a scope of the same company (an original producer) (Sasikumar and Kannan 2008; Pagell, Wu, and Murthy 2007) or the same product system (Dubreuil et al. 2010).

Economic feasibility (F4) is an important prerequisite for companies to consider involvement into new activities. This has been emphasized both for recycling processes (Hagelüken 2014) and for a closed-loop supply chain (Guide and Van Wassenhove 2009; Guide, Harrison, and Van 
Wassenhove 2003). Moreover, Guide and Van Wassenhove (2009) indicate the need for developing business opportunities for companies to get involved in product/material recovery operations, rather than put pressures on them by legislation.

For a recycler, it makes sense to operate when the value of recovered materials is higher than operation costs. R3 points out that "when material's value is not enough, there could be also fees to cover the recycling services paid by municipalities, by consumers, by government etc.” R6 indicates decreasing profit due to lower embedded value (miniaturization) (F2), complex mixes of materials per product item $(F 1)$, inefficient collection system $(F 8, F 2)$. R2 indicates that, due to high costs of recycled materials, it is more convenient for PV manufacturers to use materials that come from mines. For R4 and R5 CRM recycling is not attractive mainly due to high market instability of these materials in terms of prices $(F 3)$. R6 tried to establish CLSC with a wind turbine manufacturer, but that collaboration stopped when REE prices went down and it became cheaper to obtain materials from primary sources. Examples of R6 and R2 demonstrate that companies driven by business opportunities may change in industrial infrastructure $(F 8)$ and supply chain relations $(F 7)$. In general, the obtained evidence confirms the statement of Hagelüken (2014) and UNEP (2013) that recycling technology will be developed when business opportunities for CLSC are recognized.

It is important to take into consideration that the economic viability of recycling depends on various factors. The obtained evidence confirms indications of Hagelüken (2014) regarding such factors as material prices, $R \& D$ progress to reduce costs of the recycling processes, available volumes of items for recycling, economy of scale etc. When relying on market mechanisms, it is necessary to consider market failure to comprise all externalities such in price as an environmental impact (Morley and Eatherley 2008; Söderholm and Tilton 2012). That eventually may make recycled materials less expensive and more competitive in comparison to materials from primary sources. Hagelüken (2014) points out that it would be wrong to wait for favorable economic 
conditions to come to initiate recycling operations, as materials embedded in end-of-life product would be lost in the meantime.

Competition (F5) is experienced by recyclers in terms of loss of items that go for nonfunctional (and cheaper) recycling channels (R3, R6), ultimately damaging profitability of recycling operations $(F 2)$. R3 highlights the need for legislative support $(F 9)$ in creating an environment promoting multi-material recycling and installation of BAT at each stage of CLSC. Only R3 indicates that its CRM recycling activities give competitive advantage by providing additional source of CRMs supply for manufacturing activities and making the company less vulnerable to supply restrictions. The obtained evidence does not support the indications of previous studies for competitive advantage that CLSC brings to manufacturing companies or that CLSC can trigger competitive behavior between actors (Pagell, Wu, and Murthy 2007; Rahman and Subramanian 2012; Bell, Mollenkopf, and Stolze 2013).

Information exchange and supply chain transparency (F6) attracted least attention among companies interviewed. R3 indicates the need for process verification procedures for transparency over recycling operations and creating a level playing field for recyclers (F5). The "unpopularity" of F6 contradicts the literature that highlights importance of information exchange in CLSC development (Miemczyk, Howard, and Johnsen 2016; Roy and Whelan 1992; Besiou and Van Wassenhove 2015; Simpson 2010). In particular, Simpson (2010) argues about the power of information to identify material value, appropriate recovery options, new markets etc.; and Miemczyk, Howard, and Johnsen (2016) indicate that development and exchange of knowledge are indispensable for CLSC development. A possible explanation for "unpopularity" of F6 could be that its relevance is more evident for developed (rather than developing) CLSC. The findings of Besiou and Van Wassenhove (2015) provide implications for negative influence of competition on the willingness to share information between actors in CLSC. 
Engagement of supply chain actors $(F 7)$ is indicated by R3 as a crucial factor for CLSC

development. The company stresses importance of the dialogues between: $i$ ) product development and recycling, to facilitate disassembly and processing; ii) collection and pre-processing, to match initial sorting and mechanical separation; iii) pre-processing (mechanical part) and recycling (metallurgy), to match the processes; and $i v$ ) between recycling and mining, to operate as complementary systems. Moreover, R3 emphasizes the dynamics of these interactions: "as a new product comes to the market, these dialogues should be updated". Previous studies support the importance of engagement of supply chain actors (F7). In particular, Defee et al. (2009) argue for CLSC orientation (meaning alignment, cooperation and sharing responsibilities among supply chain members) as an important prerequisite for CLSC development. Miemczyk, Howard, and Johnsen (2016) indicate the same role of collaborative development and planning. Hagelüken (2014) stresses that interactions between supply chain actors would make more difference for CLSC development than technical feasibility of recycling. Among interviewed companies, only R3, R6 and M4 report collaboration with other supply chain actors and/or research institutes. However, the companies worked only on technological feasibility of CRM recycling, but not development of CLSC by establishing a dialogue between different companies along CLSC.

Engagement of CLSC actors is impossible without information exchange (e.g. Cao and Zhang 2011). In particular, many researchers indicate the necessity for both collaboration and information exchange for success of CLSC (Simpson 2010; Hagelüken 2014; Roy and Whelan 1992). However, Miemczyk, Howard, and Johnsen (2016) note that not all actors need to be equally involved. While engagement and collaboration with supply chain members could be selective, e.g. R6 worked together with a manufacturer on REE recycling technology development, the transparency in supply chain requires smooth flow of information through all supply chain tiers. 
Established industrial infrastructure (F8) has a great impact on the way in which recycling is performed. Recent studies indicate that CRM recycling does not always happen due to unwillingness to pay more for advanced recycling process $(F 4)$ or/and low implementation of best available technologies (BAT) (F8) (UNEP 2013; Hagelüken 2014). Hagelüken (2014) stresses importance of BAT implementation at each stage of the supply chain, because the efficiency of CLSC corresponds to the efficiency of its weakest stage. The interviewed companies indicate that a lot of products are still not efficiently collected $(\mathrm{R} 1, \mathrm{R} 6)$ and/or go to non-functional recycling (sometimes illegally) (R3, R6), creating a business environment in which it is difficult to compete for companies that perform BAT recycling and are oriented to quality of recycled materials $(F 5)$.

Legislation (F9) plays an important role for facilitating CLSC for CRM development. Attention of policy-makers to the secondary raw materials considerably enhanced recycling activities in the EU, initially with the purpose of waste reduction and material efficiency, and now also for securing the access to materials, as company R3 noted. Rahman and Subramanian (2012) finds that legislation plays the main driving force for reverse supply chain development. Besiou and Van Wassenhove (2015) also indicate the power of regulations to address all challenges pointed out in their study. Hagelüken (2014) highlights an ability of policy-makers to take a holistic perspective and consider all factors and their interdependencies.

Although European legislation enhanced the collection of end-of-life products $(F 2, F 8)$, it is oriented towards mass recycling that does not support CRM recycling (R3). Company R3 indicates the need for obligatory standards for recycling operations and process verification procedures for ensuring high quality multi-material recycling.

Nowadays there is no legislation directed specifically towards critical materials. However, the recent EU roadmap for circular economy (European Commission 2015) acknowledged the urgency to address the following problems related to CRMs: quality of recycling, standards for 
recycling processes, data availability and information exchange. In addition, Reck and Graedel (2012) and Dewulf et al. (2016) point out a need for policy initiatives at the international level.

The importance of raising public engagement (F10) is indicated by companies R1 and R3. They point out a necessity to inform and educate both customers and supply chain actors about opportunities and benefits of recycling and closing the loop in order to facilitate collection of endof-life products $(F 2)$. Thus, in general the obtained evidence supports the literature, but does not address all issues mentioned in the literature, such as concerns for environment preservation (Rahman and Subramanian, 2012).

\section{Discussion}

\section{Differences between various supply chain actors}

The empirical results presented above suggests that the companies interviewed view differently the factors influencing development of CLSC for CRM. As shown in Table 4, the PV producers (M1 and M2) mentioned only technical feasibility of recycling (F1), while two wind turbine manufacturers (M3 and M4) together referred to three factors out of ten: F1, F2 and F7. However, given empirical evidence, there is no viable ground to make consistent differentiation between manufacturers in terms of industry or supply chain position. It is possible to imply the same about the reverse supply chain operators that together indicated relevance of all ten factors, but individually mentioned different sets of factors with most common ones as F1-F4. The difference is evident between manufacturing companies and reverse supply chain operators in terms of the variety and meaning of factors indicated.

The variety of factors considered by reverse supply chain operators could indicate that they have a better understanding of requirements for enabling CLSC for CRM. This can be explained by the fact that CLSC is more related to their business models and operational environment. Moreover, the evidence collected from R3 imply that both a focus on critical materials and the integration of 
CRM recycling with manufacturing operations (in-house recycling) support a strategic view in favor of closing the loop of CRMs. The limited set of factors indicated by the manufacturers interviewed may imply that those factors provide sufficient evidence to consider CLSC for CRM as not attractive/feasible business activity, and therefore, there is no need for any further examination.

It appears that the manufacturers interviewed do not take long-term perspective on recycling and closing the loop. They prefer to postpone dealing with it when there will be need (e.g. lack of supply from traditional sources) or benefits in a short term (e.g. large volumes of collected end-oflife products). However, Alonso et al. (2007) and Tanskanen (2013) caution that recycling as a materials criticality option require technical competence and infrastructure to be in place before supply disruptions occurs.

As previously mentioned, the interviewed reverse supply chain operators and manufacturers consider technical feasibility (F1) in different ways. The core difference between these companies lies in viewing CLSC development from either a material or a product perspective corresponding to positions of reverse supply chain operators and manufacturing companies accordingly. However, according to the previous studies, it is necessary to incorporate both perspectives to ensure sustainable material use (Hagelüken 2014; Lifset and Eckelman 2013). Such contradictory perceptions of supply chain actors imply a lack of the dialogue between these operators and/or misalignment of incentives. In addition, it should be noticed that no one is currently responsible for closing the loop, and the companies are focused primarily on their own operations.

\section{Bottleneck and enabling conditions}

The interviewed companies reveal the enabling and bottleneck conditions for each factor F1F10. From Table 5 it is possible to notice that the bottlenecks and enablers were indicated mainly by reverse supply chain operators, while manufacturing companies have rather limited view on CLSC. 
The indicated bottlenecks prevail in number several enablers mentioned. Such a misbalance may explain low recycling rates of CRMs (UNEP 2013) and perception of CLSC for CRM as an unattractive business activity and a strategy for mitigation of materials criticality (Lapko, Trucco, and Nuur 2016; Mroueh et al. 2014). However, the division between enabling and bottleneck conditions is made in order to characterize the current state, and therefore, is rather indicative. Bottleneck conditions could serve as guidelines for enabling actions.

Furthermore, it is possible to notice that some bottlenecks affect multiple factors and some factors are affected by several bottlenecks. This provides implications for interdependence of factors and that challenges for CLSC for CRM not necessarily lie within a certain single factor. In particular, Hagelüken (2014) stresses that neither environmental and social concerns, nor market forces alone are sufficient enough to ensure CRM recycling and CLSC development. It is a complex system, which requires comprehensive multi-dimensional effort.

Rogers and Tibben-Lembke (1999) and Agrawal et al. (2015) point out that enablers (drivers) and bottlenecks (barriers) differ according to the context of the study, and that the same factor could be an enabler and a bottleneck in different contexts. Although the research design of the paper allows to indicate bottlenecks and enablers common for different CRMs and technologies (PV and wind turbines), and accounts for perspectives of different supply chain actors, this paper is inevitably limited to the companies, industries and CRMs considered. However, it is possible to indicate that the obtained results support previous research underlining such issues as infrastructure, technical and economic feasibility (Geyer and Jackson 2004; Besiou and Van Wassenhove 2015; Simpson 2010; Rahimifard et al. 2009). Nevertheless, the material perspective on CLSC development taken in this study allowed to obtain a greater level of details for a greater variety of factors. In addition, the paper offers empirical evidence that support insights in reports and rather conceptual papers (Eurometaux 2013; Reck and Graedel 2012). 
Table 5. Enabling and bottleneck conditions

\begin{tabular}{|c|c|c|c|c|c|c|c|c|c|c|c|c|c|c|}
\hline Enablers and bottlenecks & $E^{*}$ & $\mathrm{~B}^{*}$ & $\mathrm{R}^{*}$ & $\mathrm{M}^{*}$ & $\mathrm{~F}^{*}{ }^{*}$ & F2 & F3 & $\mathrm{F} 4$ & F5 & F6 & F7 & F8 & F9 & F10 \\
\hline $\begin{array}{l}\text { Uncertainty about volumes of returns (long product life cycle; extension } \\
\text { of product life cycle) }\end{array}$ & & $\bullet$ & $\bullet$ & $\bullet$ & & $\bullet$ & & & & & & & & \\
\hline Increase of products sold & - & & - & & & $\bullet$ & & - & & & & & & \\
\hline Miniaturization, dematerialization (low concentrations of materials) & & $\bullet$ & $\bullet$ & & - & $\bullet$ & & $\bullet$ & & & & & & \\
\hline Inefficient collection systems & & $\bullet$ & • & & & $\bullet$ & & & & & & - & & \\
\hline $\begin{array}{l}\text { Leakage of collected items to non-functional recycling (and cheaper) } \\
\text { recycling channels }\end{array}$ & & • & • & & & $\bullet$ & & & - & & & $\bullet$ & & \\
\hline Complex mixes of materials in a product item & & $\bullet$ & $\bullet$ & & $\bullet$ & & & & & & & & & \\
\hline Low implementation of recycling BAT & & $\bullet$ & $\bullet$ & & $\bullet$ & & & & & & & $\bullet$ & & \\
\hline Lack of appropriate recycling technology & & $\bullet$ & & - & $\bullet$ & & & & & & & & & \\
\hline Unwillingness to pay for more advanced recycling process & & - & - & & - & & & - & & & & & & \\
\hline Instability of market for recycled materials & & - & - & & & & - & - & & & & & & \\
\hline Higher cost of recycled materials in comparison to primary ones & & $\bullet$ & $\bullet$ & & & & & $\bullet$ & & & & & & \\
\hline Lack of demand for CRM recycled & & $\bullet$ & $\bullet$ & & & & - & & & & & & & \\
\hline $\begin{array}{l}\text { Quality of recycled materials is lower than required for considered } \\
\text { applications }\end{array}$ & & $\bullet$ & $\bullet$ & & & & $\bullet$ & & & & & & & \\
\hline Lack of interconnections between all stages of CLSC & & $\bullet$ & $\bullet$ & & & & & & & $\bullet$ & $\bullet$ & & $\bullet$ & \\
\hline Lack of process verification procedures & & $\bullet$ & $\bullet$ & & & & & & & $\bullet$ & & & $\bullet$ & \\
\hline $\begin{array}{l}\text { Legislative orientation towards mass-recycling (not multi-materials } \\
\text { recycling) }\end{array}$ & & $\bullet$ & $\bullet$ & & & & & & - & & & & & \\
\hline Legislative support for wastes reduction & $\bullet$ & & - & & & - & & & & & & & & \\
\hline Legislative support for collection of end of life products & $\bullet$ & & $\bullet$ & & & $\bullet$ & & & & & & & & \\
\hline Lack of obligatory standards for recycling operations & & - & $\bullet$ & & & & & & & & & & - & \\
\hline Lack of public engagement in recycling and closed-loop operations & & $\bullet$ & $\bullet$ & & & & & & & & & & & - \\
\hline
\end{tabular}




\section{Conclusions and further research}

This paper extends the discussion on CLSC implementation by considering CLSC with recycling as a product recovery option and by specifically focusing on closing the loop of materials embedded in products. It highlights the importance of the material perspective on CLSC development, as a dominant product perspective does not provide a necessary level of detail for examination of such systems. The empirical example of CRMs underlines the urgency of the material perspective.

The paper provides empirical evidence from multiple supply chain actors in PV and wind turbine industries that can potentially be part of CLSC for CRM. Building on the existing literature, the paper offers a list of factors for CLSC development with the focus on CRM recycling. This list can serve practitioners and policy-makers as an instrument for examination of the current state of CLSC, for better understanding of different aspects of CLSC, for enabling holistic view on CLSC development, for facilitating decision making on the actions enabling CLSC.

The obtained results suggest the diversity of views regarding CLSC for CRM implementation, and in particular, the gap between manufacturers and reverse supply chain operators. Incentive misalignment and lack of holistic view on CLSC development pushes attention of companies on their own operations rather than on search for opportunities for collaboration and new business development. Furthermore, as material flows are not limited by geographical boundaries and CLSC for CRM is rather a global system, consistent harmonization of legislation at the international arena could support closing the loops of materials and circular economy in general.

The paper also contributes to the discussion on mitigation of materials criticality by providing empirical evidence in relation to strategic viability and operational feasibility of closing the loop of CRMs through recycling. The obtained evidence on bottlenecks for implementation of CLSC for CRM provide implications for unpopularity of this strategy to mitigate materials criticality. 
Further research should address the empirical limitations of this study by examining other critical materials and industries, broader range of companies within a supply chain and from a wider geographical scope. It is necessary to investigate if development of CLSC for CRM is subject to contingencies specific to a certain industry, a supply chain or a critical material considered. Further research should focus on investigation of interconnections between applications where the same material is used, as closing the loop of a material depends on its recycling potential in all applications. Finally, it would be important to explore possible interconnections and dynamics between the considered factors.

\section{Acknowledgements}

This paper is produced as part of the EMJD Programme European Doctorate in Industrial Management (EDIM) funded by the European Commission, Erasmus Mundus Action 1.

In addition, Prof. Cali Nuur wants to acknowledge the generous grant from Marianne and Marcus Wallenberg Foundation (no. MMW 2013.0194) in contributing to this paper.

\section{References}

Agrawal, Saurabh, Rajesh K. Singh, and Qasim Murtaza. 2015. “A Literature Review and Perspectives in Reverse Logistics.” Resources, Conservation and Recycling 97: 76-92.

Allwood, Julian M, Michael F Ashby, Timothy G Gutowski, and Ernst Worrell. 2013. "Material Efficiency : Providing Material Services with Less Material Production.” Philosophical Transactions of the Royal Society (371): 1-15.

Allwood, Julian M., Michael F. Ashby, Timothy G. Gutowski, and Ernst Worrell. 2011. "Material Efficiency: A White Paper.” Resources, Conservation and Recycling 55 (3): 362-381. 
Alonso, Elisa, Jeremy Gregory, Frank Field, and Randolph Kirchain. 2007. "Material Availability and the Supply Chain : Risks , Effects , and Responses.” Environmental Science \& Technology 41 (19): 6649-6656.

Anctil, Annick, and Vasilis Fthenakis. 2013. "Critical Metals in Strategic Photovoltaic Technologies: Abundance versus Recyclability." Prog. Photovolt: Res. Appl. 21 (6): 12531259.

Bell, John E., Diane a. Mollenkopf, and Hannah J. Stolze. 2013. "Natural Resource Scarcity and the Closed-Loop Supply Chain: A Resource-Advantage View." International Journal of Physical Distribution \& Logistics Management 43 (5): 351-379.

Besiou, Maria, and Luk N. Van Wassenhove. 2015. "Closed-Loop Supply Chains for Photovoltaic Panels: A Case-Based Approach.” Journal of Industrial Ecology 20 (4): 929-937.

Buchert, Matthias, Doris Schüler, and Daniel Bleher. 2009. “Critical Metals For Future Sustainable Technologies And Their Recycling Potential.” Darmstadt, Germany : Öko-Institut \& UNEPDTIE.

Burrell, J. 2009. "The Field Site as a Network: A Strategy for Locating Ethnographic Research.” Field Methods 21 (2): 181-199.

Cao, Mei, and Qingyu Zhang. 2011. "Supply Chain Collaboration: Impact on Collaborative Advantage and Firm Performance." Journal of Operations Management 29 (3): 163-180.

Carter, Craig R., and Lisa M. Ellram. 1998. "Reverse Logistics: A Review of the Literature and Framework for Future Investigation.” Journal of Business Logistics 19 (1): 85-102.

Ciacci, Luca, Barbara K Reck, N T Nassar, and T. E. Graedel. 2015. "Lost by Design.” 
Environmental Science \& Technology 49 (16): 9443-9451.

Defee, C Clifford, Terry Esper, and Diane Mollenkopf. 2009. "Leveraging Closed-Loop Orientation and Leadership for Environmental Sustainability." Supply Chain Management: An International Journal 14 (2): 87-98.

Dewulf, Jo, Gian Andrea Blengini, David Pennington, Philip Nuss, and Nedal T. Nassar. 2016. “Criticality on the International Scene: Quo Vadis?” Resources Policy 50: 169-176.

Dowlatshahi, Shad. 2000. "Developing a Theory of Reverse Logistics.” Interfaces 30 (3): 143-155.

Dubreuil, Alain, Steven B. Young, John Atherton, and Thomas P. Gloria. 2010. "Metals Recycling Maps and Allocation Procedures in Life Cycle Assessment.” International Journal of Life Cycle Assessment 15 (6): 621-634.

Eisenhardt, Kathleen. 1989. "Building Theories from Case Study Research.” Academy of Management Review 14 (4): 532-550.

Eisenhardt, Kathleen, and M. E. Graebner. 2007. “Theory Building from Cases: Opportunities and Challenges." Academy of Management Journal 50 (1): 25-32.

Elshkaki, Ayman, and T. E. Graedel. 2014. "Dysprosium, the Balance Problem, and Wind Power Technology." Applied Energy 136: 548-559.

Eurometaux. 2013. "Boosting Recycling to Support Access to Raw Material and Resource Efficiency.” Brussels, Belgium.

European Commission. 2010. "Critical Raw Materials for the EU. Report of the Ad-Hoc Working Group on Defining Critical Raw Materials.” Brussels, Belgium. 
—_. 2011. "Energy Roadmap 2050.” Brussels, Belgium.

- 2014. "Report on Critical Raw Materials for the EU. Report of the Ad-Hoc Working Group on Defining Critical Raw Materials.” Brussels, Belgium.

—. 2015. "Roadmap on Circular Economy Strategy.” Brussels, Belgium.

Flint, Daniel J, Robert B Woodruff, and Sarah Fisher Gardial. 2002. “Customers' Desired Value Change in a Business-to-Business Context.” Journal of Marketing 66 (4): 102-117.

Geyer, Roland, and Tim Jackson. 2004. "Supply Loops and Their Constraints: The Industrial Ecology of Recycling and Reuse." California Management Review 46 (2): 55-73.

Geyer, Roland, Brandon Kuczenski, Trevor Zink, and Ashley Henderson. 2015. “Common Misconceptions about Recycling.” Journal of Industrial Ecology 20 (5): 1010-1017.

Govindan, Kannan, Hamed Soleimani, and Devika Kannan. 2015. "Reverse Logistics and ClosedLoop Supply Chain : A Comprehensive Review to Explore the Future." European Journal of Operational Research 240 (3): 603-626.

Graedel, T. E., Julian Allwood, Jean-Pierre Birat, Matthias Buchert, Christian Hagelüken, Barbara K. Reck, Scott F. Sibley, and Guido Sonnemann. 2011. "What Do We Know About Metal Recycling Rates?” Journal of Industrial Ecology 15 (3): 355-366.

Graedel, T. E., Rachel Barr, Chelsea Chandler, Thomas Chase, Joanne Choi, Lee Christoffersen, Elizabeth Friedlander, et al. 2012. "Methodology of Metal Criticality Determination." Environmental Science \& Technology 46 (2): 1063-70.

Green, Nicola. 1999. "Disrupting the Field. Virtual Reality Technilogies and 'Multisited' Ethnographic Methods.” American Behavioral Scientist 43 (3): 409-421. 
Guba, Egon G. 1981. "ERIC/ECTJ Annual Review Paper: Criteria for Assessing the Trustworthiness of Naturalistic Inquiries.” Educational Communication and Technology 29 (2): 75-91.

Guide, V. Daniel R., Terry P. Harrison, and Luk N. Van Wassenhove. 2003. "The Challenge of Closed-Loop Supply Chains." Interfaces 33 (6): 3-6.

Guide, V. Daniel R., and Luk N. Van Wassenhove. 2009. “OR FORUM-The Evolution of ClosedLoop Supply Chain Research.” Operations Research 57 (1): 10-18.

Hagelüken, Christian. 2014. "Recycling of ( Critical ) Metals.” In Critical Metals Handbook, edited by Gus Gunn, 41-69. John Wiley \& Sons.

Hirschman, Elizabeth. 1986. "Humanistic Inquiry in Marketing Research : Philosophy, Method, and Criteria.” Journal of Marketing Research 23 (3): 237-249.

IEA. 2013. “Technology Roadmap: Wind Energy.” Paris, France.

—. 2014. “Techology Roadmap. Solar Photovoltaic Energy.” Paris, France.

Knemeyer, A. Michael, Thomas G. Ponzurick, and Cyril M. Logar. 2002. “A Qualitative Examination of Factors Affecting Reverse Logistics Systems for End-of-life Computers.” International Journal of Physical Distribution \& Logistics Management 32 (6): 455-479.

Lapko, Yulia, Paolo Trucco, and Cali Nuur. 2016. “The Business Perspective on Materials Criticality : Evidence from Manufacturers.” Resources Policy 50: 93-107. doi:10.1016/j.resourpol.2016.09.001.

Lau, Kwok Hung, and Yiming Wang. 2009. "Reverse Logistics in the Electronic Industry of China: A Case Study." Supply Chain Management: An International Journal 14 (6): 447-465. 
Licht, Christina, Laura Talens Peiro, and Gara Villalba. 2015. “Global Substance Flow Analysis of Gallium, Germanium, and Indium: Quantification of Extraction, Uses, and Dissipative Losses within Their Anthropogenic Cycles.” Journal of Industrial Ecology 19 (5): 890-903.

Lifset, Reid, and Matthew Eckelman. 2013. "Material Efficiency in a Multi-Material World.” Philosophical Transactions of the Royal Society of London A: Mathematical, Physical and Engineering Sciences 371: 1-13.

Lin, Yong, and Li Zhou. 2011. "The Impacts of Product Design Changes on Supply Chain Risk: A Case Study." International Journal of Physical Distribution \& Logistics Management 41 (2): $162-186$.

Manuj, Ila, and John T. Mentzer. 2008. "Global Supply Chain Risk Management Strategies.” International Journal of Physical Distribution \& Logistics Management 38 (3): 192-223.

Miemczyk, Joe, Mickey Howard, and Thomas E. Johnsen. 2016. “Dynamic Development and Execution of Closed-Loop Supply Chains: A Natural Resource-Based View.” Supply Chain Management: An International Journal 21 (4): 453-469.

Miles, H., and M. Huberman. 1994. Qualitative Data Analysis: A Sourcebook. Sage Publications, Beverly Hills, CA.

Mollenkopf, Diane, Ivan Russo, and Robert Frankel. 2007. "The Returns Management Process in Supply Chain Strategy.” International Journal of Physical Distribution \& Logistics Management 37 (7): 568-592.

Morley, Nick, and Dan Eatherley. 2008. "Material Security. Ensuring Resource Availability for the UK Economy.” Oakedene Hollins; C-Tech Innovation: Chester, UK. 
Moss, R.L., E. Tzimas, P. Willis, J. Arendorf, L.Tercero Espinoza, Paul Thompson, Adrian Chapman, et al. 2013. Critical Metals in the Path towards the Decarbonisation of the EU Energy Sector. Petten, the Netherlands: Joint Research Center.

Mroueh, Ulla-Maija, John Bacher, Henna Punkkinen, Aymeric Brunot, Lisa Bolin, Selim Stahl, Kristina Bette, Katharina Mattes, and Catherine Joce. 2014. "CRM Supply-Chain Analysis of Energy , ICT and Electronics and Transport Sectors. CRM_InnoNet Deliverable Report D4.4.”

Nadai, Eva, and Christoph Maeder. 2005. "Fuzzy Fields. Multi-Sited Ethnography in Sociological Research.” Forum: Qualitative Social Research 6 (3).

NRC. 2008. Minerals, Critical Minerals, and The U.S. Economy. Edited by The National Academies Press. Washington, DC.

Pagell, Mark, and Zhaohui Wu. 2009. "Building A More Complete Theory Of Sustainable Supply Chain Management Using Case Studies Of 10 Exemplars.” Journal of Supply Chain Management 45 (2): 37-56.

Pagell, Mark, Zhaohui Wu, and Nagesh N. Murthy. 2007. "The Supply Chain Implications of Recycling." Business Horizons 50 (2): 133-143.

Panwar, N. L., S. C. Kaushik, and Surendra Kothari. 2011. "Role of Renewable Energy Sources in Environmental Protection: A Review." Renewable and Sustainable Energy Reviews 15 (3): $1513-1524$.

Peck, David, Prabhu Kandachar, and Erik Tempelman. 2015. "Critical Materials from a Product Design Perspective.” Materials \& Design 65: 147-159.

Porter, Michael E. 1979. "How Competitive Forces Shape Strategy.” Harvard Business Review 57 
(2): $137-145$.

Rahimifard, S., G. Coates, T. Staikos, C. Edwards, and M. Abu-Bakar. 2009. "Barriers, Drivers and Challenges for Sustainable Product Recovery and Recycling.” International Journal of Sustainable Engineering 2 (2): 80-90.

Rahman, Shams, and Nachiappan Subramanian. 2012. "Factors for Implementing End-of-Life Computer Recycling Operations in Reverse Supply Chains.” International Journal of Production Economics 140 (1): 239-248.

Reck, B. K., and T. E. Graedel. 2012. “Challenges in Metal Recycling.” Science 337 (2011): 690695.

Rogers, DS, and R. Tibben-Lembke. 1999. Going Backwards: Reverse Logistics Trends and Practices. Reno, NV: Reverse Logistics Executive Council.

Roy, R, and R C Whelan. 1992. "Successful Recycling Through Value-Chain Collaboration.” Long Range Planning 25 (4): 62-71.

Sasikumar, P., and G Kannan. 2008. "Issues in Reverse Supply Chains, Part I: End-of-life Product Recovery and Inventory Management-an Overview.” International Journal of Sustainable Engineering 1 (3): 154-172.

Saunders, Mark, Philip Lewis, and Adrian Thornhill. 2009. Research Methods for Business Students. Harlow: Prentice Hall.

Simpson, Dayna. 2010. "Use of Supply Relationships to Recycle Secondary Materials." International Journal of Production Research 48 (1): 227-249.

Söderholm, Patrik, and John E. Tilton. 2012. "Material Efficiency: An Economic Perspective." 
Resources, Conservation and Recycling 61: 75-82.

Souza, Gilvan C. 2013. "Closed-Loop Supply Chains: A Critical Review, and Future Research*." Decision Sciences 44 (1): 7-38.

Speirs, Jamie, and Bill Gross. 2014. Materials Availability for Low-Carbon Technologies : An Assessment of the Evidence. London: UK Energy Research Centre.

Sprecher, Benjamin, Rene Kleijn, and Gert Jan Kramer. 2014. "Recycling Potential of Neodymium: The Case of Computer Hard Disk Drives." Environmental Science and Technology 48 (16): 9506-9513.

Stindt, Dennis, Joao Quariguasi Frota Neto, Christian Nuss, Martin Dirr, Marta Jakowczyk, Andrew Gibson, and Axel Tuma. 2016. "On the Attractiveness of Product Recovery: The Forces That Shape Reverse Markets." Journal of Industrial Ecology: 1-15.

Strauss, Anselm, and Juliet Corbin. 1990. Basic of Qualitative Research: Grounded Theory Procedures Atnd Technique. Newbury Park, CA: Sage Publications.

Tanskanen, Pia. 2013. "Management and Recycling of Electronic Waste.” Acta Materialia 61 (3): $1001-1011$.

Thierry, Martijn, Marc Salomon, Jo Van Nunen, and Luk N Van Wassenhove. 1995. "Strategic Issues in Product Recovery Management.” California Management Review 37 (2): 114-135.

U.S. Department of Energy. 2011. "Critical Materials Strategy.” Washington, DC: U.S. Department of Energy.

UNEP. 2013. "Metal Recycling: Opportunities, Limits, Infrastructure. A Report of the Working Group on the Global Metal Flows to the International Resource Panel." 
Wallendorf, Melanie, and Russell Belk. 1989. “Assessing Trustworthiness in Naturalistic Consumer Research.” In Interpretive Consumer Research, edited by Elizabeth Hirschman, 69-84. Provo, UT : Association for Consumer Research.

Yin, Robert K. 2009. Case Study Research Design and Methods. Thousand Oaks: Sage Publications. 